\title{
Mechanisms of Inhibition of Fungi in Agar by Streptomycetes
}

\author{
By S. C. HSU AND J. L. LOCKWOOD \\ Department of Botany and Plant Pathology, Michigan State University, \\ East Lansing, Michigan, U.S.A. 48823
}

(Accepted for publication 24 March 1969)

\section{SUMMARY}

Of 20 unidentified Streptomyces isolates tested, all inhibited Mucor ramannianus and 18 inhibited Glomerella cingulata in agar. Agar discs from inhibition zones, or paper discs placed beneath inhibition zones, of nine of the Streptomyces isolates caused new inhibition zones when transferred to fresh, seeded agar plates. Transferable inhibition zones were not produced by the other I I isolates. Inhibitory substances were produced in liquid cultures by eight of the nine isolates which produced them in agar media, whereas no antibiotics were detected in liquid cultures of the other I I isolates. Glomerella cingulata conidia, which do not require exogenous nutrients for germination, germinated in liquid cultures of non-antibiotic-producing streptomycetes, but failed to germinate in cultures of antibiotic-producing streptomycetes. Inhibition zones produced by non-antibiotic streptomycetes decreased in size with increasing concentration of nutrients, whereas those of antibiotic streptomycetes were unchanged. Glucose and glutamic acid levels in agar rapidly decreased adjacent to streptomycete colonies. Agar, leached of nutrients by sterilized distilled water running slowly through a groove cut in the agar, developed clear inhibition zones. Therefore, inhibition of fungi by streptomycetes in agar, in some cases, appears to be due to nutrient deprivation.

\section{INTRODUCTION}

Many streptomycetes inhibit fungi and other micro-organisms in artificial media. However, about half of those which show antagonism on solid media fail to produce any detectable inhibitory substances in liquid media containing the same nutrient materials (Florey et al. 1949; Schatz \& Hazen, I948; Stessel, Leben \& Keitt, I953; Waksman, 1945; Waksman, 1967). The reasons for this are not understood, but it is generally assumed that cultural conditions are somehow less favourable for antibiotic production in liquid than on solid media (Florey et al. 1949).

Recent information from this laboratory indicated that fungal spores may fail to germinate in soil because micro-organisms deplete nutrients rather than form inhibitory substances (Lockwood, I964; Ko \& Lockwood, I967). Among other lines of evidence, the inhibition of spore germination on agar placed in contact with soil correlated with the loss of nutrients from the agar rather than with the diffusion of fungistatic materials into the agar. The purpose of this study was to investigate the mechanisms of the inhibition of fungi by streptomycetes in agar, and particularly to determine if nutrient depletion might be a mechanism of antagonism. 


\section{METHODS}

Preparation of streptomycetes and fungi. Twenty unidentified Streptomyces isolates from soil and the test fungi, Glomerella cingulata and Mucor ramannianus, were maintained on potato glucose agar. Conidia of $G$. cingulata required no exogenous nutrients for germination, whereas those of $M$. ramannianus required an exogenous carbon source. Conidia were removed from the surface of agar slopes with sterilized distilled water.

Assays of inhibition zones. Tests for inhibitory activity were made in Petri dishes on peptone agar (per litre: peptone, $5 \mathrm{~g}$.; agar, $20 \mathrm{~g}$.) and peptone glucose agar (per litre: peptone, $5 \mathrm{~g}$.; glucose, $5 \mathrm{~g}$.; agar, $20 \mathrm{~g}$.). Streptomycetes were streaked on the media, and incubated for 2 or 3 days at $24^{\circ}$. Then conidial suspensions of Glomerella cingulata or Mucor ramannianus were sprayed on to the agar surface with a modified Stansly's spray apparatus (Johnson, Curl, Bond \& Fribourg, 1959). Approximately $2.5 \times 10^{5}$ spores were sprayed on to each plate. After 3 days the inhibition zones were measured.

The presence of antibiotics in the inhibition zones was tested by three methods. (i) Agar discs, $7 \mathrm{~mm}$. in diam., were cut from inhibition zones and transferred to the surface of peptone agar and peptone glucose agar, or to Petri dishes without agar, and allowed to incubate without supplying additional inoculum of the test fungus. Presence or absence of growth of the test fungus was observed. (ii) Agar discs, $7 \mathrm{~mm}$. in diam., were cut from inhibition zones and transferred to the surface of peptone agar and peptone glucose agar. Immediately or several hours later a spore suspension of the same test fungus was sprayed on to the agar surface. The presence or absence of new inhibition zones was observed. (iii) Sterile filter paper discs, $13 \mathrm{~mm}$. in diam., were placed beneath the agar of the inhibition zones for Io to 15 days to allow any inhibitory substances to diffuse into the paper discs. The discs were then transferred to the surface of peptone agar and peptone glucose agar, and the test fungus was sprayed on the agar surface. The development of any new inhibition zones was observed.

Assays of lytic zones. Mycelia of Glomerella cingulata were prepared by mixing conidia with warm $\left(42^{\circ}\right)$ peptone agar at the rate of $4000 / \mathrm{ml}$. The agar was then poured into Petri dishes and incubated for 2 to 3 days. Mycelia grew primarily within the agar, producing a dense, uniform growth with relatively few appressed hyphae on the surface. Streptomyces isolates were then streaked on the surface of the agar. At io, 25 and 30 days, agar discs, $7 \mathrm{~mm}$. in diam., were cut from lytic zones and transferred to peptone agar and peptone glucose agar. A spore suspension of $G$. cingulata was sprayed on to the surface of the agar to test for the presence of diffusible inhibitory substances. Other discs were transferred to peptone agar containing growing mycelium of $G$. cingulata to test for diffusible lytic substances.

Detection of antibiotics. Streptomycetes were cultured in $125 \mathrm{ml}$. Erlenmeyer flasks containing $20 \mathrm{ml}$. liquid medium per flask. The media were: (i) Bacto (Difco) nutrient broth, 6 g.; glucose, 5 g.; $\mathrm{NaCl}, 5 \mathrm{~g}$.; $\mathrm{ZnSO}_{4} .7 \mathrm{H}_{2} \mathrm{O}$, 0.0I g.; $\mathrm{CaCO}_{3}, 3.5 \mathrm{~g}$.; distilled water, $1000 \mathrm{ml}$; (ii) peptone, $5 \mathrm{~g}$; glucose, $5 \mathrm{~g}$.; distilled water, $1000 \mathrm{ml}$. Streptomyces isolates were grown in duplicate shaken flasks for 3 days at $24^{\circ}$. Sterilized Millipore filters $(0.22 \mu)$ were used to obtain sterile culture filtrates. Five ml. of each filtrate were applied to $13 \mathrm{~mm}$. diam. paper discs by applying samples of $0.1 \mathrm{ml}$., then alternately air-drying the discs. The discs were placed on the surface of $0.5 \%$ peptone 
agar. The test fungus, Glomerella cingulata, was then sprayed on the agar surface. The assay plates were incubated at $24^{\circ}$ for 3 days, when the zones of inhibition were observed. Control discs containing $5 \mathrm{ml}$. uninoculated media gave no inhibition zones.

Utilization of nutrients in agar. An agar medium was prepared containing: glucose, 2 g.; glutamic acid, 2 g.; $\mathrm{KH}_{2} \mathrm{PO}_{4}, 5.3 \mathrm{~g}$.; $\mathrm{K}_{2} \mathrm{HPO}_{4} ; 10.6$ g.; agar, $25 \mathrm{~g}$.; distilled water, I000 $\mathrm{ml}$. This medium, adjusted to $\mathrm{pH} 7 \cdot 0$, supported good growth of the test fungi and streptomycetes. To prepare an agar layer of uniform thickness, a top layer of $5 \mathrm{ml}$. was poured over a base layer of $5 \mathrm{ml}$. Four Streptomyces isolates were streaked on the agar surface. On the Ist, 2nd, $4^{\text {th }}$ and 6th days, six agar discs, $7 \mathrm{~mm}$. in diam., from the top layer of agar near the streptomycete colonies were removed and melted in $3 \mathrm{ml}$. glass-distilled water. Glucose was assayed enzymically (Keston, 1956) by the Glucostat reagent (Worthington Biochemical Corporation, Freehold, New Jersey), used according to the manufacturer's directions. Glutamic acid was assayed by melting three discs in $6 \mathrm{ml}$. glass-distilled water, using the ninhydrin method (Moore \& Stein, 1954).

All experiments included several replicates and were done at least twice with similar results.

\section{RESULTS}

Inhibition characteristics of streptomycetes. Of the 20 streptomycetes, 18 caused inhibition zones ( 3 to $19 \mathrm{~mm}$.) when Glomerella cingulata was used as the test organism (Table I). Agar discs from the original inhibition zones of nine isolates caused new inhibition zones when transferred to fresh agar plates seeded with $G$. cingulata (Table I). New inhibition zones were also produced by these isolates when paper discs placed beneath the original inhibition zones were transferred to fresh seeded agar. When agar discs from the original inhibition zones were transferred to fresh agar or to Petri dishes without agar, the test fungus failed to grow on discs of the same nine isolates. These results showed that diffusible inhibitory substances were produced by nine of the streptomycetes. Zone sizes for these isolates ranged from 12 to $19 \mathrm{~mm}$., with a mean of $17 \mathrm{~mm}$.

Neither agar discs from zones produced by the other nine antagonistic isolates nor paper discs from beneath such zones produced inhibition zones on fresh agar media seeded with Glomerella cingulata. Agar from zones produced by these isolates supported growth of the test fungus when discs were transferred to fresh agar or to Petri dishes without agar. The sizes of inhibition zones for these isolates ranged from 3 to $15 \mathrm{~mm}$., with a mean of $8 \mathrm{~mm}$. pH changes (from 6.9 to $8 \pm 0.5$ ) brought about in the agar by growth of the streptomycetes did not account for the inhibition since (i) $G$. cingulata grew well in that $\mathrm{pH}$ range, and (ii) similar inhibition zones occurred in media buffered with $0 \cdot 1 \mathrm{M}$-phosphate, except where, in three instances, the buffer depressed growth of the streptomycetes.

Very similar results were obtained when Mucor ramannianus was used as the test fungus. All 20 Streptomyces isolates caused inhibition zones ( 7 to $19 \mathrm{~mm}$.) on agar media. The same nine isolates produced inhibition zones, and the test fungus failed to grow on excised agar discs from these inhibition zones, even when a drop of $0.2 \%$ glucose solution was added to the agar discs. Zone sizes for these isolates ranged from 14 to $19 \mathrm{~mm}$., with a mean of $17 \mathrm{~mm}$.

The other II isolates did not produce transferable inhibition zones and excised 
agar discs from these original inhibition zones supported growth of the test fungus when a drop of glucose solution was added. The sizes of inhibition zones for these isolates ranged from 7 to $16 \mathrm{~mm}$., with a mean of $\mathrm{II} \mathrm{mm}$.

Lysis characteristics of streptomycetes. Thirteen Streptomyces isolates produced zones of complete or partial lysis of Glomerella cingulata mycelium after 10 days incubation (Table 2). After 30 days, the sizes of these lytic zones had increased and five additional isolates had made small lytic zones.

\section{Table I. Inhibition characteristics of streptomycetes against Glomerella cingulata in agar tests}

\begin{tabular}{|c|c|c|c|c|c|}
\hline \multirow{3}{*}{$\begin{array}{l}\text { Streptomycos } \\
\text { isolates }\end{array}$} & \multirow{3}{*}{$\begin{array}{c}\text { Original } \\
\text { inhibition } \\
\text { zone } \\
(\mathrm{mm} .)^{\bullet}\end{array}$} & \multicolumn{4}{|c|}{ Inhibition characteristics of agar from inhibition zones } \\
\hline & & \multicolumn{2}{|c|}{ New inhibition zones $(\mathrm{mm}.) \dagger$} & \multicolumn{2}{|c|}{ Growth of test fungus $\ddagger$} \\
\hline & & Agar & Paper discs & Agar & Paper discs \\
\hline I A & 18 & 8 & 9 & - & - \\
\hline $2 \mathrm{~A}$ & 18 & 8 & 9 & - & - \\
\hline $4 \mathrm{~A}$ & 18 & 9 & I0 & - & - \\
\hline $6 \mathrm{~A}$ & 15 & 10 & 10 & - & - \\
\hline $7 \mathrm{~A}$ & 18 & 6 & 4 & - & - \\
\hline IOA & 19 & 10 & 10 & - & - \\
\hline $16 \mathrm{~A}$ & 12 & 5 & 7 & - & - \\
\hline $24 \mathrm{~A}$ & 15 & 8 & 8 & - & - \\
\hline $28 \mathrm{~A}$ & 19 & 13 & I0 & - & - \\
\hline $3 \mathrm{~A}$ & 13 & 0 & 0 & + & + \\
\hline $8 \mathrm{~A}$ & 15 & 0 & 0 & + & + \\
\hline $5 \mathrm{~A}$ & 0 & . & 0 & . & . \\
\hline $9 \mathrm{~A}$ & 3 & 0 & 0 & + & + \\
\hline $12 \mathrm{~A}$ & 4 & 0 & 0 & + & + \\
\hline $13 \mathrm{~A}$ & 4 & 0 & 0 & + & + \\
\hline $15 \mathrm{~A}$ & 3 & 0 & 0 & + & + \\
\hline $17 \mathrm{~A}$ & 13 & 0 & 0 & + & + \\
\hline $18 \mathrm{~A}$ & 4 & 0 & 0 & + & + \\
\hline $19 \mathrm{~A}$ & 10 & 0 & 0 & + & + \\
\hline $26 \mathrm{~A}$ & 0 & . & 0 & . & . \\
\hline
\end{tabular}

* Streptomycetes were streaked on the agar. After 3 days, conidia of $G$. cingulata were sprayed on the agar suface.

$\dagger$ Agar discs from inhibition zones or paper discs placed beneath the inhibition zones were transferred to fresh agar subsequently sprayed with conidia of $G$. cingulata.

$\ddagger$ Agar discs from inhibition zones were transferred to unseoded agar or to Petri dishes without agar;,$-=$ no growth of test fungus:,$+=$ growth of test fungus.

Agar discs from lytic zones of these 18 streptomycetes were transferred to fresh test fungal cultures, but none made new lytic zones. The nine isolates which had earlier produced transferable inhibition zones again caused such zones on fresh, seeded peptone agar, and the other nine lytic isolates did not. Therefore, the lytic zones produced by the latter isolates must have been caused by factors other than antibiotics or diffusible lytic factors. At 30 days, the sizes of lytic zones containing antibiotics ranged from Io to $15 \mathrm{~mm}$., average $13 \mathrm{~mm}$. The sizes of lytic zones without antibiotics ranged from 2 to $12 \mathrm{~mm}$., average $7 \mathrm{~mm}$.

Antibiotic production in liquid media. Sterile culture filtrates of 8 isolates (I A, 2 A, $4 \mathrm{~A}, 6 \mathrm{~A}, 10 \mathrm{~A}, \mathrm{I} 6 \mathrm{~A}, 24 \mathrm{~A}$ and $28 \mathrm{~A}$ ) contained antibiotic substances; these isolates all produced transferable inhibition zones on agar. Filtrates of eight other isolates $(3 \mathrm{~A}$, 
5A, 7A, 8A, A9, I2A, I3A, I8A) contained no detectable inhibitory substances. Except for isolate $7 \mathrm{~A}$, these isolates did not produce transferable inhibition zones on agar plates. Isolate $7 \mathrm{~A}$ grew poorly in the liquid media, which may account for its failure to produce antibiotics.

Table 2. Lysis of Glomerella cingulata by streptomycetes in agar

\begin{tabular}{|c|c|c|c|c|}
\hline \multirow[b]{2}{*}{$\begin{array}{l}\text { Streptomyces } \\
\text { isolates }\end{array}$} & \multicolumn{2}{|c|}{ Original lytic zone (mm.) } & \multicolumn{2}{|c|}{ Effect of transferred lytic zone } \\
\hline & $\begin{array}{c}\text { IO } \\
\text { days }\end{array}$ & $\begin{array}{l}30 \\
\text { days }\end{array}$ & $\begin{array}{l}\text { Lytic } \\
\text { zone }\end{array}$ & $\begin{array}{c}\text { Inhibition } \\
\text { zone (mm.) }\end{array}$ \\
\hline $1 \mathrm{~A}$ & 3 & 14 & 0 & 8 \\
\hline $2 \mathrm{~A}$ & 6 & 15 & 0 & 8 \\
\hline $4 \mathrm{~A}$ & 6 & 10 & 0 & 6 \\
\hline $6 \mathrm{~A}$ & 4 & 13 & 0 & 7 \\
\hline $7 \mathrm{~A}$ & 5 & 15 & 0 & 3 \\
\hline $10 \mathrm{~A}$ & 5 & 15 & 0 & 8 \\
\hline I6 A & 3 & 10 & 0 & 6 \\
\hline $24 \mathrm{~A}$ & 6 & 12 & 0 & 6 \\
\hline $28 \mathrm{~A}$ & 8 & 15 & 0 & 8 \\
\hline $3 \mathrm{~A}$ & 6 & 8 & 0 & 0 \\
\hline $5 \mathrm{~A}$ & 0 & 0 & . & . \\
\hline $8 \mathrm{~A}$ & 7 & 12 & 0 & o \\
\hline $9 \mathrm{~A}$ & 0 & 4 & 0 & o \\
\hline $12 \mathrm{~A}$ & o & 6 & 0 & 0 \\
\hline I $3 \mathrm{~A}$ & 0 & 8 & 0 & 0 \\
\hline $15 \mathrm{~A}$ & 0 & 0 & . & . \\
\hline $17 \mathrm{~A}$ & 3 & 8 & 0 & 0 \\
\hline $18 \mathrm{~A}$ & 0 & 2 & 0 & 0 \\
\hline $19 \mathrm{~A}$ & 4 & 12 & 0 & 0 \\
\hline $26 \mathrm{~A}$ & 0 & 2 & 0 & 0 \\
\hline
\end{tabular}

* Agar discs from lytic zones were transferred to agar containing mycelium or conidia of $G$. cingulata.

Fungal spore germination in streptomycete cultures. Four Streptomyces isolates were selected for further study. Isolates I A and 4A produced inhibitory substances; $3 \mathrm{~A}$ and $8 \mathrm{~A}$ did not. Conidia of Glomerella cingulata, which do not require exogenous nutrients for germination, were incubated in 3-day-old liquid cultures of these streptomycetes for $14 \mathrm{hr}$ and germination was determined. In each of three experiments 150 to 180 spores were counted in each of 10 microscopic fields. Low mean levels of germination, II \% and $18 \%$, occurred in cultures of isolates I A and $4 \mathrm{~A}$, respectively (Fig. I) and were not significantly altered when potato broth was added at the time conidia were introduced. By contrast, high degrees of germination, $77 \%$ and $72 \%$, occurred in cultures of $3 \mathrm{~A}$ and $8 \mathrm{~A}$, respectively. When potato broth was added, $98 \%$ of $G$. cingulata conidia germinated.

Effect of nutrient enrichment on inhibition zones. Isolates $1 \mathrm{~A}, 3 \mathrm{~A}, 4 \mathrm{~A}$ and $8 \mathrm{~A}$ were streaked on agar media containing nine different concentrations $(0.2$ to $4.0 \%)$ of peptone and glucose. After 3 days, conidia of Mucor ramannianus, a species requiring exogenous nutrients for germination, were sprayed on the agar surface. The size of inhibition zones produced by isolates $3 \mathrm{~A}$ and $8 \mathrm{~A}$ decreased with increasing nutrient concentration (Fig. 2). Agar discs from these inhibition zones produced no new inhibition zones when transferred to fresh seeded agar, and the test fungus grew when similar agar discs were transferred to unseeded agar. The sizes of inhibition zones produced by isolates $\mathrm{I} A$ and $4 \mathrm{~A}$ did not decrease with nutrient concentration; agar 


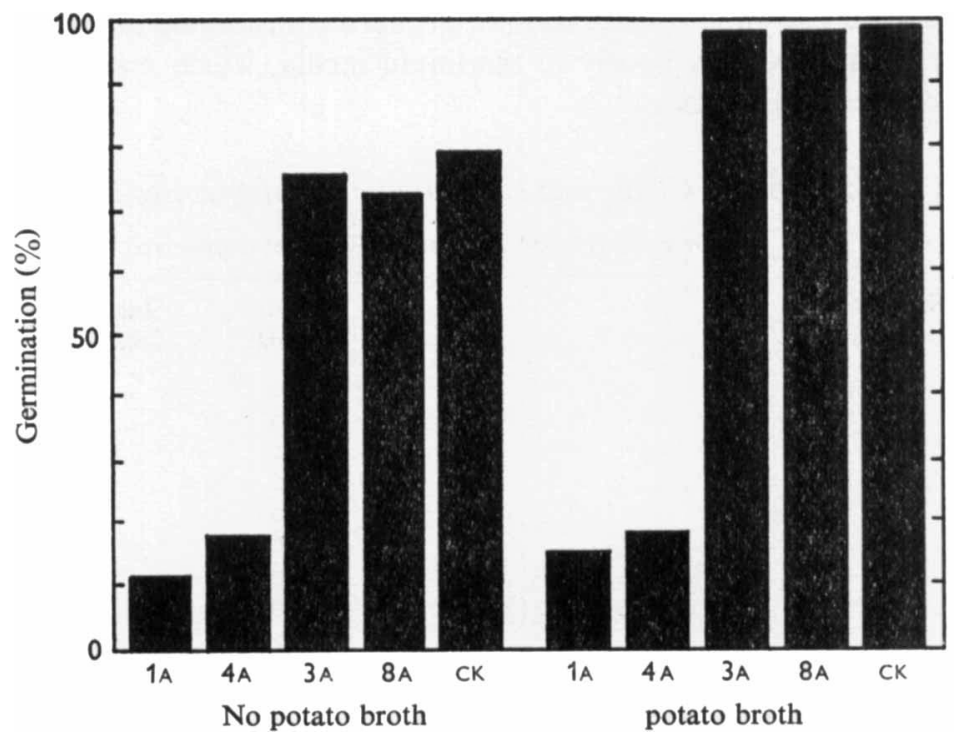

Fig. I. Germination of Glomerella cingulata conidia in antibiotic (I A and $4 \mathrm{~A}$ ) and non-antibiotic (3 A and $8 \mathrm{~A}$ ) streptomycete cultures.

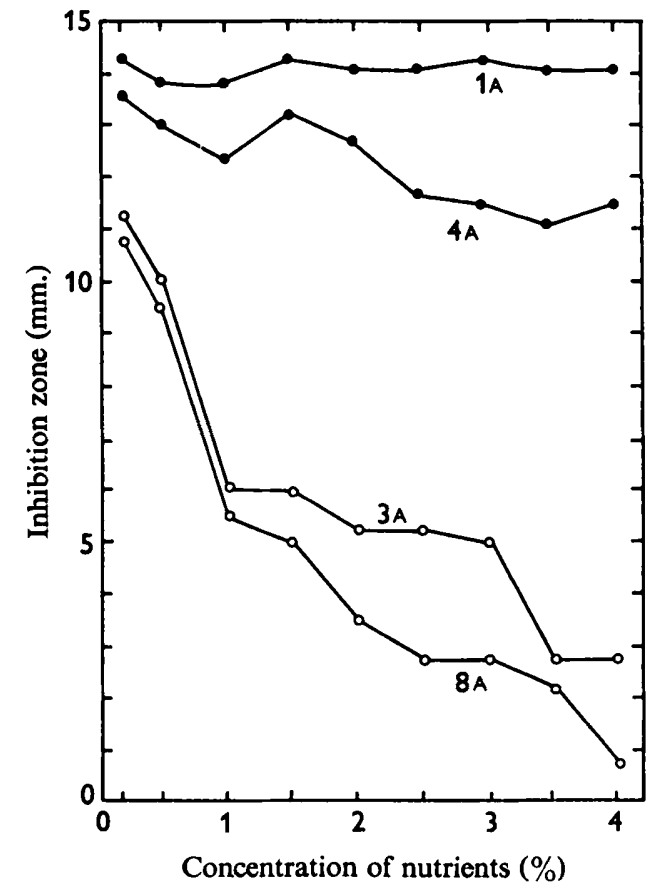

Fig. 2. Effect of concentration of glucose and peptone in agar on size of inhibition zones of Mucor ramannianus produced by antibiotic ( $\mathrm{I} \mathrm{A}$ and $4 \mathrm{~A}$ ) and non-antibiotic ( $3 \mathrm{~A}$ and $8 \mathrm{~A}$ ) streptomycetes. 
discs from these inhibition zones produced new inhibition zones when transferred to fresh seeded agar, and the test fungus did not grow when similar agar discs were transferred to unseeded agar.

Nutrient status of agar adjacent to streptomycete colonies. Glucose was rapidly lost from the agar within $7 \mathrm{~mm}$. of streaks of isolates I A, 3A, 4A and 8A: 60 to $70 \%$ was lost by the 2 nd day, and 80 to $90 \%$ was lost by the 6th day (Fig. 3). Glutamic

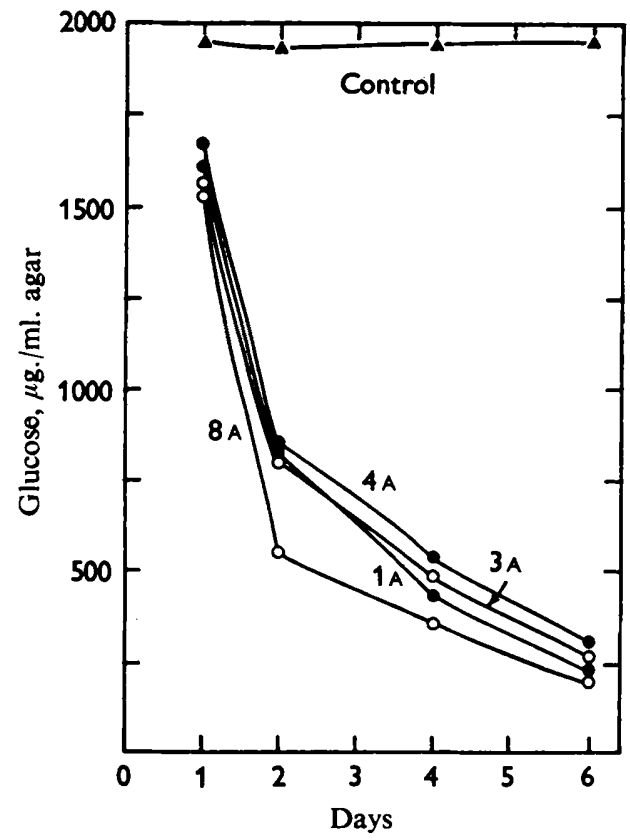

Fig. 3

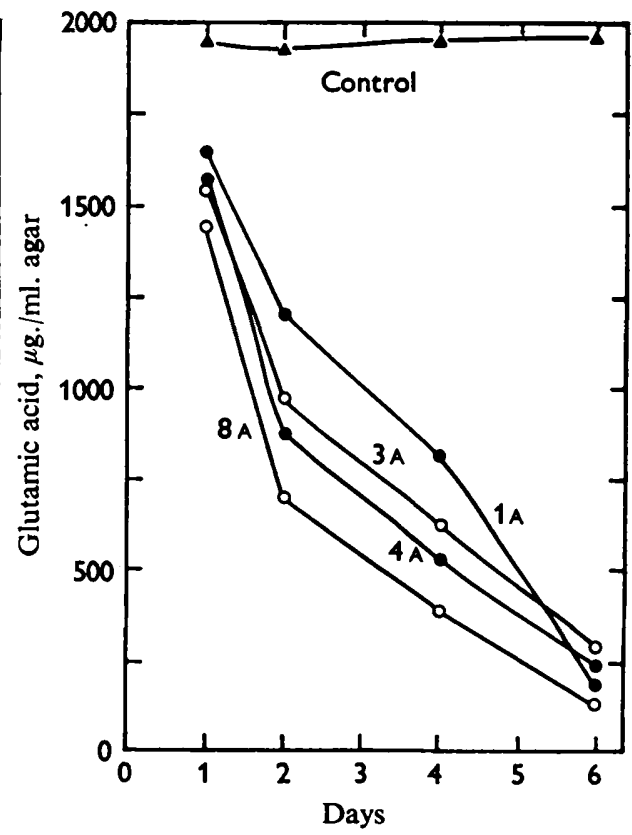

Fig. 4

Fig. 3. Loss of glucose from agar in $7 \mathrm{~mm}$. diam. discs immediately adjacent to antibiotic ( $\mathrm{A}$ and $4 \mathrm{~A}$ ) and non-antibiotic (3 A and $8 \mathrm{~A}$ ) streptomycetes. Agar contained $0.2 \%$ glucose and $0.2 \%$ glutamic acid. Control was agar without streptomycetes.

Fig. 4. Loss of glutamic acid from agar in $7 \mathrm{~mm}$. diam. discs immediately adjacent to antibiotic ( $\mathrm{A} \mathrm{A}$ and $4 \mathrm{~A}$ ) and non-antibiotic (3 A and $8 \mathrm{~A}$ ) streptomycetes. Agar contained $0.2 \%$ glucose and $0.2 \%$ glutamic acid. Control was agar without streptomycetes.

acid was also rapidly utilized by the four streptomycetes: more than $75 \%$ was lost by the 6th day (Fig. 4). As with peptone-glucose agar, discs from the agar adjacent to isolate I A and $4 \mathrm{~A}$, when transferred to fresh seeded agar, made new inhibition zones, but discs from the agar adjacent to isolate $3 \mathrm{~A}$ or $8 \mathrm{~A}$ did not make new inhibition zones.

Effect of glucose and glutamic acid concentration on germination of conidia of Mucor ramannianus. A low level $(250 \mu \mathrm{g} . / \mathrm{ml}$.), approximating to the amount of each compound remaining in the agar after the 5 th day, and a high level $(2 \mathrm{mg} . / \mathrm{ml}$., the initial concentration) were prepared in the following mineral salt solution: $\mathrm{NaNO}_{3}, 2 \mathrm{~g}$.; $\mathrm{K}_{2} \mathrm{HPO}_{4}$, I g.; $\mathrm{MgSO}_{4} .7 \mathrm{H}_{2} \mathrm{O}, 0.5 \mathrm{~g}$.; $\mathrm{KCl}, 0.5 \mathrm{~g}$.; $\mathrm{FeSO}_{4} .7 \mathrm{H}_{2} \mathrm{O}$, 0.0I g.; water, I000 $\mathrm{ml}$. Glucose and glutamic acid at $250 \mu \mathrm{g} . / \mathrm{ml}$. supported about $45 \%$ germination of Mucor spores, and $2 \mathrm{mg}$. $/ \mathrm{ml}$. supported about $80 \%$ germination. The relatively lower amount of germination occurring at $250 \mu \mathrm{g}$. $/ \mathrm{ml}$. may explain the occurrence of 
the inhibition zones. Moreover, the depletion of nutrients would continue after the germination of the conidia, and the germ tubes would be exposed to an increasingly deprived environment. Observation of conidia of test fungi in inhibition zones showed that although some germination occurred, the germ tubes were unable to develop.

Inhibition zones produced in leached agar. To determine directly whether exhaustion of nutrients from agar can cause inhibition zones on agar, the following experiment was devised. A special Petri dish was prepared with the cover fitted with an inlet tube and the bottom with an outlet tube. The inlet tube was connected by vinyl tubing to a separatory funnel containing sterilized distilled water placed above the Petri dish. The outlet tube was similarly connected to a flask placed below the Petri dish. The entire system was autoclaved and maintained in a sterile condition. Twenty $\mathrm{ml}$. of $0.5 \%$ peptone glucose agar was poured into the Petri dish. A strip of agar about $7 \mathrm{~mm}$. wide was removed, and replaced with a smaller amount of melted agar to seal the two semicircles of agar. The dish was tilted slightly and sterile distilled water was allowed to drip into one end of the groove and run out the other end into the sterile flask. The rate of water flow into the agar plate was adjusted to about 0.5 to $0.8 \mathrm{ml} . /$ min. and continued for 7 days. At this time conidia of Mucor ramannianus or Glomerella cingulata were sprayed on the agar surface. Water was again allowed to run through the system for 3 more days, during which time clear inhibition zones about $10 \mathrm{~mm}$. wide had developed on either side of the groove (Fig. 5). The spores of the test fungi in the inhibition zones had germinated poorly. When agar discs from these inhibition zones were transferred to fresh peptone agar, the conidia of both fungi germinated and developed mycelia. No contaminating microorganisms developed. Analysis of the agar in the zones showed that more than $90 \%$ of the glucose and amino acid were lost during the I0-day period of the experiment. Therefore, leaching of nutrients from agar can make inhibition zones which duplicate in every way those produced by streptomycetes.

\section{DISCUSSION}

Eleven of the 20 inhibitory streptomycetes tested produced inhibition zones by a mechanism which did not involve antibiotics. Evidence for the lack of antibiotics may be summarized as follows: (i) Antibiotics could not be demonstrated in agar from inhibition zones or in paper discs placed beneath agar in inhibition zones; (ii) on excised agar from these inhibition zones, the nutrient-independent conidia of Glomerella cingulata germinated, and the nutrient-dependent conidia of Mucor ramannianus germinated when glucose was added; (iii) cultures of the same isolates in liquid media also failed to produce detectable antibiotics; (iv) conidia of $G$. cingulata germinated freely when incubated in cultures of these streptomycetes. By contrast, the nine other streptomycetes showed evidence for the presence of antibiotics in these tests.

Evidence that inhibition by non-antibiotic isolates was due to an induced deficiency of nutrients in the agar is: (i) sizes of inhibition zones produced by non-antibiotic streptomycetes decreased, whereas those produced by antibiotic streptomycetes were unchanged, when concentrations of nutrients in the medium were increased; (ii) glucose and glutamic acid were rapidly depleted to suboptimal levels in agar media adjacent to streptomycete colonies; (iii) agar, artificially deprived of nutrients by leaching, failed to support spore germination and mycelial growth. Such agar gave inhibition zones which resembled those produced by streptomycetes. 
The failure of conidia of Glomerella cingulata to germinate in inhibition zones of non-antibiotic streptomycetes requires explanation, since it is nutrient-independent. Germination of $G$. cingulata conidia and some other nutrient-independent spores is known to be inhibited by artificial nutrient sinks, and their failure to germinate on soil has been explained on the basis of the nutrient sink provided by soil microorganisms (Ko \& Lockwood, 1967). The fact that agar in the inhibition zones produced by two antibiotic-producing streptomycetes was also rapidly deprived of nutrients raises a question as to the relative importance of antibiotics and nutrient depletion in production of inhibition zones by streptomycetes which produce antibiotics. Nutrient deprivation as an antagonistic mechanism in agar should also be evaluated for bacteria and fungi.

Although 18 Streptomyces isolates lysed fungal mycelia, in no case did agar discs from lytic zones make new lytic zones on fresh fungal cultures. However, new inhibition zones were made by those isolates shown to produce antibiotics. Therefore, the production of lytic zones can not be attributed to antibiotics or to any demonstrable diffusible lytic factors. Evidence that nutrient deprivation is involved in inducing autolysis of fungi in soil has been presented by Lloyd \& Lockwood (I966). In view of the ability of four of the streptomycetes to effectively deplete agar of nutrients, it may be that lytic zones on agar result from nutrient deprivation.

Much research in plant pathology has dealt with determination of numbers of antagonistic micro-organisms in soils (Kaufman \& Williams, 1965; Wood \& Tveit, 1955). Attempts are often made to correlate populations of antagonists with incidence of disease in certain soil types or following some kind of soil treatment. Assessment of numbers of antagonists and degree of antagonism are done in agar tests. It is usually stated or implied that these data provide a measure of the numbers of organisms capable of producing antibiotics active against a given pathogenic fungus. The results of this research suggest that interpretation of these kinds of data on the basis of antibiotic production may be erroneous without further examination of the mechanism involved.

This research was done as part of the North Central Regional Experiment Station Project 'Mechanisms of Survival of Root Infecting Fungi in Soil' (NC-70), and is published as Journal Article no. 456I of the Michigan Agricultural Experiment Station.

\section{REFERENCES}

Florey, H. W., Chain, E., Heatley, N. G., Jennings, M. A., Sanders, A. G., Abraham, E. P. \& Florey, M. E. (1949). Antibiotics, vol. I, London: Oxford University Press.

Johnson, L. F., Curl, E. A., Bond, J. H. \& Fribourg, H. A. (1959). Methods for Studying Soil Microflora-Plant Disease Relationships, Minneapolis, Minn., U.S.A.: Burgess Publishing Co.

Kaufman, D. D. \& Williams, L. E. (1965). Influence of soil reaction and mineral fertilization on numbers and types of fungi antagonistic to four soil-borne plant pathogens. Phytopathology $\mathbf{5 5}$, 570.

Keston, A.S. (1956). Specific colorimetric enzymatic analytical reagents for glucose. Abstr. Pap. I 29 th meeting Am. Chem. Soc. no. $31 \mathrm{C}$.

Ko, W. H. \& Lockwood, J. L. (1967). Soil fungistasis: relation to fungal spore nutrition. Phytopathology 57, 894 .

Lockwood, J. L. (1964). Soil fungistasis. A. Rev. Phytopathol. 2, 341.

LLOYD, A. B. \& LockWOOD, J. L. (I966). Lysis of fungal hyphae in soil and its possible relation to autolysis. Phytopathology 56, 595 . 
MOORE, S. \& STEIN, W. H. (I954). A modified ninhydrin reagent for the photometric determination of amino acids and related compounds. J. biol. Chem. $211,907$.

SchatZ, A. \& HaZEN, E. L. (1948). The distribution of soil micro-organisms antagonistic to fungi pathogenic for man. Mycologia 40, $46 \mathrm{I}$.

Stessel, G. J., Leben, C. \& Keitr, G. W. (1953). Screening tests designed to discover antibiotics suitable for plant disease control. Mycologia 45, 325.

Waksman, S. A. (1945). Microbial Antagonisms and Antibiotic Substances. New York, N.Y., U.S.A.: The Commonwealth Fund.

Waksman, S. A. (1967). The Actinomycetes, a Summary of Current Knowledge. New York, N.Y., U.S.A.: Ronald Press.

Wood, R. K. S. \& TVErT, M. (1955). Control of plant diseases by use of antagonistic organisms. Bot. Rev. 2I, 441 .

\section{EXPLANATION OF PLATE}

Inhibition zone of Glomerella cingulata produced in leached agar. 
Journal of General Microhiology, Vol. 57, No. 2

Plate I

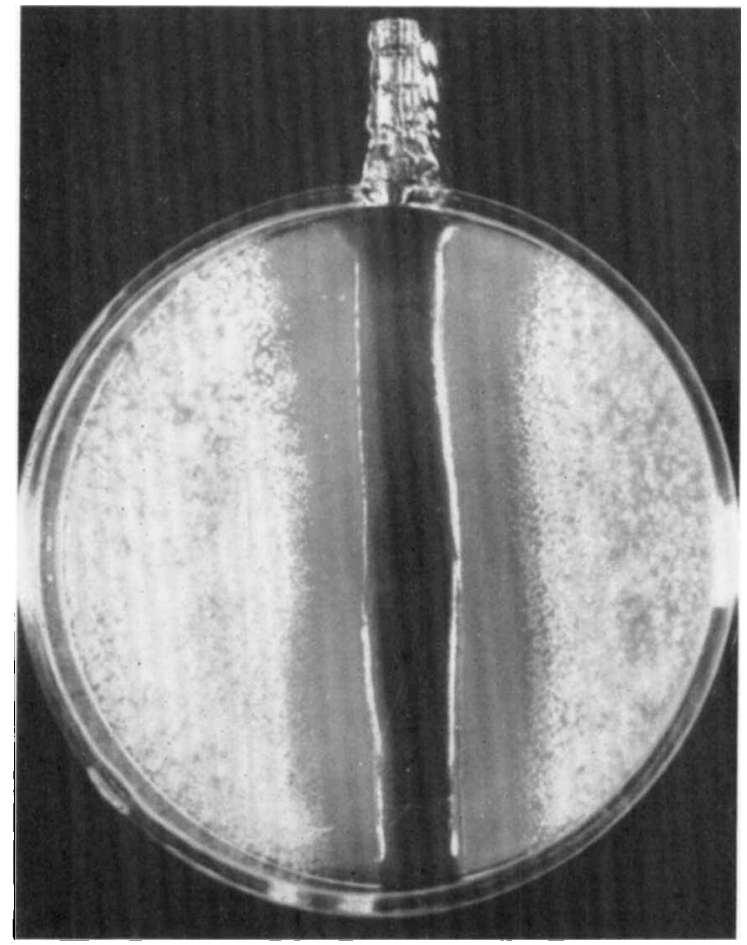

